\title{
Delayed drainage of aquitard in response to sudden change in groundwater level in adjacent confined aquifer: Analytical and experimental studies
}

\author{
ZHOU ZhiFang*, GUO QiaoNa \& DOU Zhi \\ School of Earth Sciences and Engineering, Hohai University, Nanjing 210098, China
}

Received September 28, 2012; accepted January 20, 2013; published online March 11, 2013

\begin{abstract}
The problem of the groundwater dynamics and water balance of a confined aquifer in the aquifer system has been solved in previous studies, whereas that in the aquitard adjacent to the confined aquifer has seldom been considered. In reality, the groundwater dynamics of the aquitard are closely related to the exploitation of groundwater resources, groundwater contamination, underground storage utilization and land subsidence. In this paper, an analytical solution is derived to describe the drawdown variation in the aquitard when the head in the adjacent confined aquifer declines by a constant value. The characteristics of groundwater dynamics and water balance of the aquitard are analyzed using a dimensionless analytical solution. There is obvious delayed behavior in the response of groundwater dynamics in the aquitard, which is characterized by the delay index $\tau_{0}$. The delayed behavior in the response of groundwater dynamics is not only dependent on the properties of the aquitard, but also proportional to the square of the thickness of the aquitard. The law of the delayed release of water is described in terms of the ratio of the delayed release of water. A water balance equation for the aquitard is established. Three stages of the water balance and the corresponding characteristics are presented with the water balance curves of the aquitard. The analytical solution is given to analyze the flux per unit horizontal area of the aquitard. The hydrogeological parameters of the aquitard, namely the hydraulic conductivity, specific storativity and hydraulic diffusivity, are estimated according to type-curve fitting between the analytical solution and observed flux. The parameters are identified and validated in an experiment.
\end{abstract}

aquitard, water balance, parameter identification, delayed release of water

Citation: Zhou Z F, Guo Q N, Dou Z. Delayed drainage of aquitard in response to sudden change in groundwater level in adjacent confined aquifer: Analytical and experimental studies. Chin Sci Bull, 2013, 58: 3060-3069, doi: 10.1007/s11434-013-5730-5

The vertical profile of an alluvial plain is generally composed of several aquifers and aquitards. The aquifers and aquitards form a complex multi-layered aquifer system. For instance, the thickness of Quaternary deposits reaches 50-200 $\mathrm{m}$ on the alluvial plain downstream from the Yangtze River, namely the Yangtze Delta of China. The structure and distribution of the Quaternary deposits have several characteristics: (1) the structure has several aquifers and aquitards; (2) the spatial distribution and type of the aquifers are different in different areas; (3) the aquitards in the aquifer system are widely distributed and have large thickness, with the aquitard thickness accounting for more than

*Corresponding author (email: zhouzf@hhu.edu.cn)
$50 \%$ of the thickness of the aquifer system in some areas; and (4) the permeability of the aquifers is two or more orders of magnitude greater than that of the aquitards. With the development of urbanization, various groundwater resources and environmental problems arise. For example, the total area of land that has subsided by more than $200 \mathrm{~mm}$ due to excessive groundwater extraction accounts for onetenth of China's Yangtze River Delta, which covers an area of $99000 \mathrm{~km}^{2}$. Accumulated subsidence has reached a maximum of $2.8 \mathrm{~m}$, and has caused economic losses of up to 50 billion dollars. As a result, groundwater contamination has extended from shallow aquifers to deep aquifers.

The aquitard is too frequently ignored or treated as an impermeable boundary in the study of the groundwater flow 
of aquifers. It is mainly because of our subjective understanding that the aquitard is regarded as a relatively impermeable layer; i.e. water resources stored in aquitards are considered to be small. In reality, significant sources of groundwater are stored in aquitards and can be used for water supply and depleted [1]. The non-zero permeability of an aquitard has been demonstrated through laboratory measurements [2-4] and regional groundwater flow modeling [5]; permeability values vary over a large range from $10^{-15}$ to $10^{-23} \mathrm{~m}^{2}[6]$.

In recent years, there has been much research on the well hydraulics of aquifer-aquitard systems. In many cases, the drawdown in an aquitard greatly affects the flow in an adjacent aquifer. For instance, Sun and Zhan [7] studied the flow in an aquifer-aquitard system by considering the storativity of the aquitard and three dimensional flows in the aquifer. Malama et al. [8] presented a semi-analytical solution for flow in a leaky unconfined aquifer-aquitard system. Malama et al. [9] solved the flow problem in a system comprising two aquifers and one aquitard in which the top unconfined aquifer is pumped by a partially penetrating well. The process of poroelastic release in the aquitard induced by pumping of the aquifer has been considered [10]. Yeh and Chang [11] reviewed recent advances in well hydraulics in an aquifer-aquitard system. Most previous studies focused on the groundwater dynamics and water balance of the aquifer in an aquifer-aquitard system. However, few studies considered the characteristics of groundwater dynamics and water balance of the aquitard adjacent to the confined aquifer.

Scholars have investigated the relationship between dewatering and consolidation of the soil layer, because soil deformation is related to pore water pressure $[12,13]$. However, previous studies only focused on the mechanical properties of pore water and soil deformation, not the char- acteristics of the groundwater dynamics and water balance. In addition, few methods have been considered for determining hydrogeological parameters of the aquitard. Especially, there is a lack of an effective experimental method for estimating hydrogeological parameters. In reality, the groundwater dynamics of the aquitard are closely related to the exploitation of groundwater resources, groundwater contamination, underground storage utilization and land subsidence. The aquitard is an important part of the aquifer system. The groundwater dynamics and water balance are of great importance not only to the prediction, evaluation and control of land subsidence but also to groundwater resource development, evaluation and calculation, and analysis of contaminant and heat transport in the aquifer system.

In this paper, the analytical solution for the drawdown variation in an adjacent aquitard is derived, under the condition that the head in the confined aquifer declines by a constant value. The characteristics of groundwater dynamics and water balance of the aquitard are analyzed. Additionally, a new method for determining the hydrogeological parameters is presented, and the estimated parameters are validated by experiment.

\section{Groundwater dynamics in the aquitard}

\subsection{Analytical solution of the flow model}

We consider a multi-layered aquifer-aquitard system consisting of an unconfined aquifer, a confined aquifer and a leaky aquitard between them as shown in Figure 1. All the layers extend infinitely laterally. Each layer is horizontal and homogeneous, and has constant thickness. The confined aquifer has an impermeable bottom. It is assumed that the groundwater level of the multilayered aquifer-aquitard system is horizontal and uniform at initial time. The hydraulic

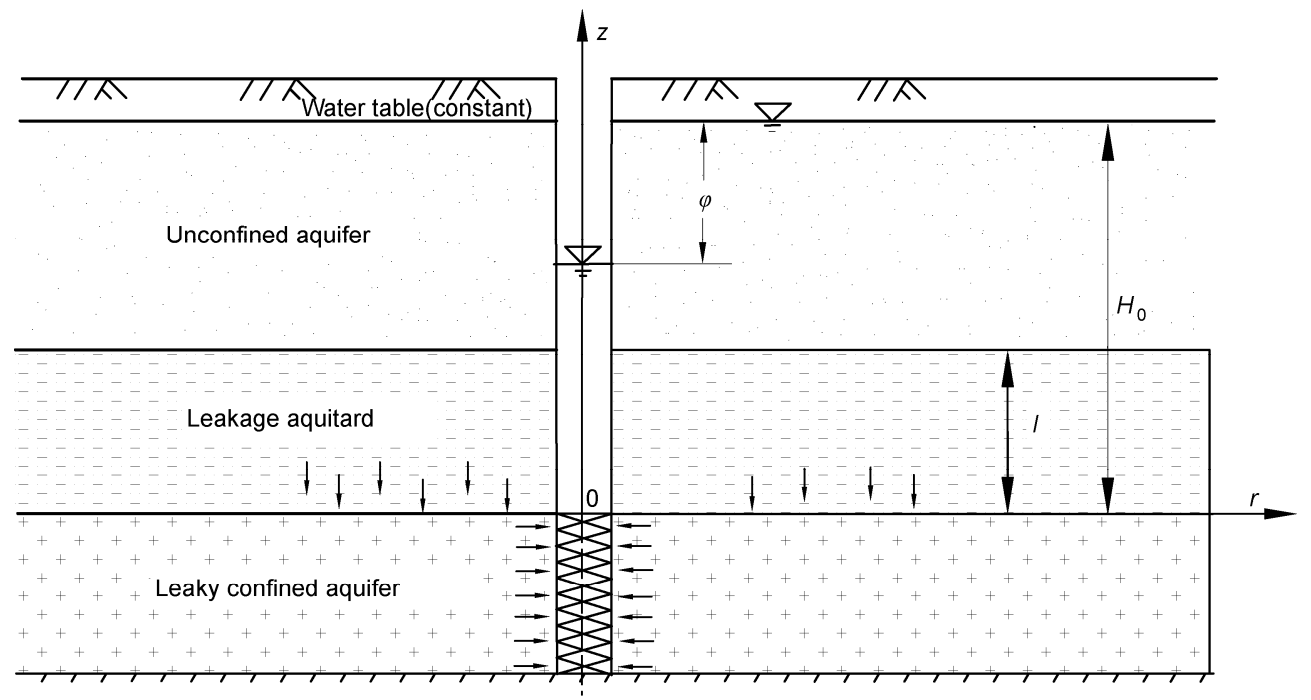

Figure 1 Conceptual model of the multi-layered aquifer-aquitard system. 
head of the confined aquifer then drops by $\varphi$, while the water table of the upper unconfined aquifer does not change. The flow is horizontal and radial in the confined aquifer, whereas it is vertical in the aquitard $[14,15]$.

Cartesian coordinates $z, r$ are used, with $z$ taken to be positive vertically upwards. The origin is located at the intersection of the $z$-axis and the bottom of the aquitard. At initial time $t=0$, the head in the multi-layered aquifer-aquitard system is uniform and equals a constant $H_{0}$, which is the distance from the groundwater level to any convenient reference.

It is assumed that there is only Darcy flow without consideration of a critical hydraulic gradient. The instantaneous linear elastic response of media to change in the effective stress in the aquitard is ignored. The drawdown response in the aquitard, $u$, due to declining head in the lower confined aquifer is determined by solving the flow problem

$$
a^{2} \frac{\partial^{2} u}{\partial z^{2}}=\frac{\partial u}{\partial t}, \quad t>0, \quad 0<z<l
$$

where $u(z, t)$ denotes the drawdown in the aquitard at location $z$ and time $t, l$ is the thickness of the aquitard, and $a^{2}$ is the hydraulic diffusivity of the aquitard (defined as the hydraulic conductivity, $K$, divided by the specific storage, $\mu_{\mathrm{s}}$ ). Eq. (1) is solved subject to the following initial and boundary conditions:

$$
\begin{gathered}
u(z, 0)=0, \quad 0<z<l, \\
u(0, t)=\varphi, \quad t>0, \\
u(l, t)=0, \quad t>0,
\end{gathered}
$$

where $\varphi$ is the drawdown of the confined aquifer at location $z=0$ and time $t$.

For the flow model above, by separating variables and taking the Fourier transform, the analytical solution is obtained as

$$
u(z, t)=\varphi\left(1-\frac{z}{l}\right)-\frac{2 \varphi}{\pi} \sum_{n=1}^{\infty} \frac{1}{n} \mathrm{e}^{-\frac{n^{2} \pi^{2} a^{2}}{l^{2}} t} \sin \frac{n \pi z}{l} .
$$

\subsection{Groundwater dynamics in the aquitard}

To discuss the groundwater dynamics in the aquitard after the head reduces in the confined aquifer, for convenience, we express eq. (5) in a dimensionless form:

$$
\bar{u}(\bar{z}, \bar{t})=\frac{u(z, t)}{\varphi}=(1-\bar{z})-\frac{2}{\pi} \sum_{n=1}^{\infty} \frac{1}{n} \mathrm{e}^{-n^{2} \pi^{2} \bar{t}} \sin n \pi \bar{z},
$$

where $\bar{u}(\bar{z}, \bar{t})$ is the dimensionless drawdown, $\bar{z}=\frac{z}{l}$ is the dimensionless length in the $z$ direction, and $\bar{t}=\frac{a^{2}}{l^{2}} t$ denotes the dimensionless time.
Figure 2 shows how the dimensionless drawdown $\bar{u}(\bar{z}, \bar{t})$ changes with dimensionless length $\bar{z}$ for different values of dimensionless time $\bar{t}$. One can see obvious curvature of the drawdown curves at the beginning time. At the bottom of the aquitard, the drawdown responds quickly to the head declining. The shorter the time, the larger the curvature of the drawdown curve. However, at the top of the aquitard, the variation in drawdown is small, indicating that the response of the head is slow. As time passes, the drawdown response extends to the entire aquitard. When the dimensionless time $\bar{t}$ increases to 1.0 , the distribution of drawdown in the aquitard forms a triangle, which results from the fact that the variation in drawdown in the aquitard is almost synchronous with that in the confined aquifer.

Using eq. (5), the delayed drawdown $p(z, t)$ in the aquitard is defined as

$$
p(z, t)=\frac{2 \varphi}{\pi} \sum_{n=1}^{\infty} \frac{1}{n} \mathrm{e}^{-\frac{n^{2} \pi^{2} a^{2}}{l^{2}} t} \sin \frac{n \pi z}{l} .
$$

Through non-dimensional transformation, Eq. (7) can be written as

$$
\bar{p}(\bar{z}, \bar{t})=\frac{p(z, t)}{\varphi}=\frac{2}{\pi} \sum_{n=1}^{\infty} \frac{1}{n} \mathrm{e}^{-n^{2} \pi^{2} \bar{t}} \sin n \pi \bar{z},
$$

where $\bar{p}(\bar{z}, \bar{t})$ is defined as the delayed drawdown response function of the aquitard, describing the dynamic dissipation process of delayed drawdown in the vertical profile.

Figure 3 shows that the dissipation of delayed drawdown is consistent with the drawdown variation in the aquitard. At the early stage, the delayed drawdown in the lower part of the aquitard dissipates rapidly, and the curvature of the drawdown curves is large; however, in the upper part of the aquitard, the delayed drawdown dissipates slowly. As time passes, the delayed drawdown in the lower aquitard dissipates slowly, and the curvature of the drawdown curve

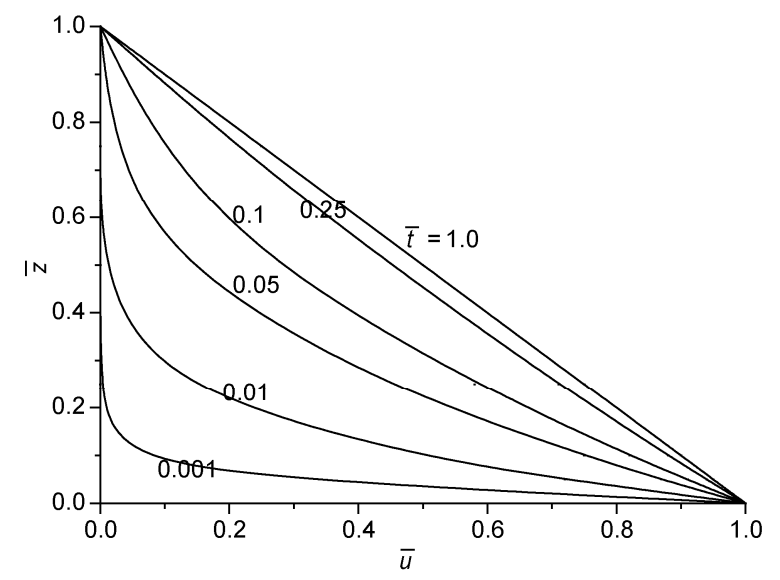

Figure 2 Changes of the dimensionless drawdown $\bar{u}(z, t)$ with $\bar{z}$ for different values of $\bar{t}$ in the aquitard. 


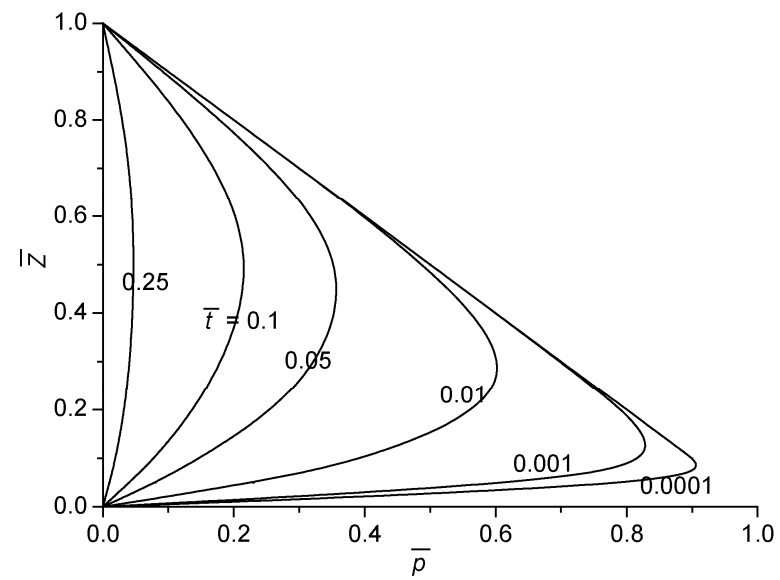

Figure 3 Changes of the delayed drawdown $\bar{p}(z, t)$ with $\bar{z}$ for different values of $\bar{t}$ in the aquitard.

becomes significantly smaller. When the dimensionless time $\bar{t}$ is 1.0 , the delayed drawdown in the entire aquitard dissipates completely.

Supposing the corresponding time $t$ equals $\tau_{0}$, one has

$$
\bar{t}=\frac{a^{2}}{l^{2}} \tau_{0}=1 \text {. }
$$

Using eq. (9), it follows that

$$
\tau_{0}=\frac{l^{2}}{a^{2}} .
$$

Here, we define $\tau_{0}$ as the delay index. When time $t \geqslant \tau_{0}$, the delayed drawdown in the entire aquitard dissipates to as low as zero. Therefore, $\tau_{0}$ is defined as the delay index, which indicates the delay time of the hydraulic response in the aquitard. The delay index $\tau_{0}$ is only dependent on the properties and thickness of the aquitard. However, it is found that the properties of the confined aquifer have less effect on the delay index.

\section{Groundwater balance of the aquitard}

\subsection{Delayed release of water from the aquitard}

The total released water per unit horizontal area of the aquitard at time $t$ is

$$
\begin{aligned}
F & =\mu_{\mathrm{s}} \int_{0}^{l} u \mathrm{~d} z \\
& =\mu_{\mathrm{s}} \int_{0}^{l} \varphi\left[\left(1-\frac{z}{l}\right) \mathrm{d} z-\mu_{\mathrm{s}} \int_{0}^{l} \frac{2 \varphi}{\pi} \sum_{n=1}^{\infty} \frac{1}{n} \mathrm{e}^{-\frac{n^{2} \pi^{2} a^{2}}{l^{2}} t} \sin \frac{n \pi z}{l} \mathrm{~d} z\right] \\
& =\frac{1}{2} \mu_{\mathrm{s}} \varphi l-\frac{2}{\pi^{2}} \mu_{\mathrm{s}} \varphi l \sum_{n=1}^{\infty} \frac{1}{n^{2}} \mathrm{e}^{-\frac{n^{2} \pi^{2} a^{2}}{l^{2}}}\left(1-(-1)^{n}\right) .
\end{aligned}
$$

As time $t \rightarrow \infty$, the drawdown of the aquitard tends to- ward a steady state. The total released water per unit horizontal area of the aquitard is then

$$
F_{0}=\frac{1}{2} \mu_{\mathrm{s}} \varphi l
$$

From eqs. (11) and (12), the delayed release of water per unit horizontal area of the aquitard at time $t$ is

$$
\Delta F=F_{0}-F=\frac{2}{\pi^{2}} \mu_{\mathrm{s}} \varphi l \sum_{n=1}^{\infty} \frac{1}{n^{2}} \mathrm{e}^{-\frac{n^{2} \pi^{2} a^{2}}{l^{2}}}\left(1-(-1)^{n}\right) .
$$

Thus, the ratio of the delayed release of water $\theta$ is defined as

$$
\theta=\frac{\Delta F}{F_{0}}=\frac{8}{\pi^{2}} \mathrm{e}^{-\frac{\pi^{2} a^{2}}{l^{2}} t}=\frac{8}{\pi^{2}} \mathrm{e}^{-\pi^{2} \bar{t}}
$$

The ratio of the delayed release of water $\theta$ describes the amount of delayed-release water released at time $t$ relative to the total amount released in the aquitard. Figure 4 shows that, as the dimensionless time $\bar{t}$ increases, the ratio of the delayed release of water $\theta$ drops rapidly. Within initial time of $\tau_{0} / 5,85 \%$ of the delayed release of water releases in the aquitard. The ratio of delayed release of water $\theta$ then changes with dimensionless time $\bar{t}$ slightly. When $t=\tau_{0}$, all the delayed release of water in the aquitard has released.

\subsection{Groundwater balance of the aquitard}

According to Darcy's law, the flux per unit horizontal area at position $z$ and time $t$ can be expressed as

$$
\begin{aligned}
q(z, t) & =K J(z, t)=K \frac{\partial u}{\partial z} \\
& =-\frac{1}{l} K \varphi-\frac{2}{l} K \varphi \sum_{n=1}^{\infty} \mathrm{e}^{-\frac{n^{2} \pi^{2} a^{2}}{l^{2}} t} \cos \frac{n \pi z}{l}
\end{aligned}
$$

The cumulative flux per unit horizontal area at location $z$ during time $t$ is

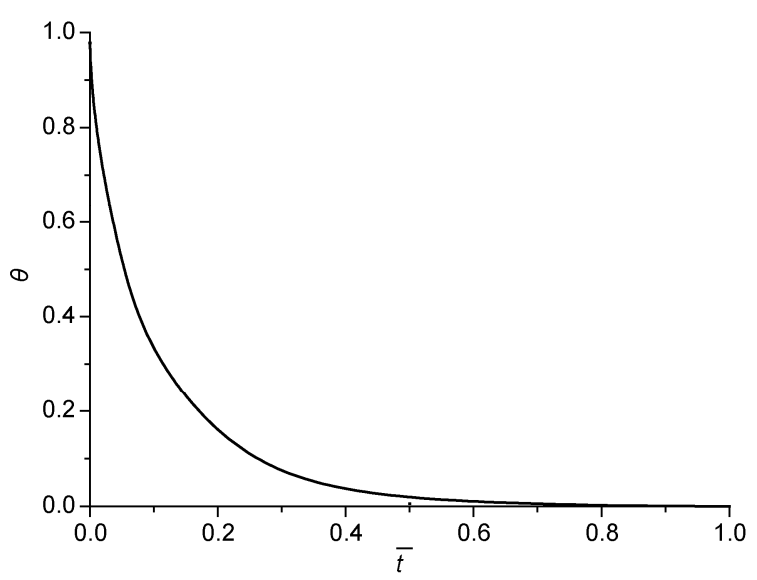

Figure 4 Change of the ratio of delayed release of water $\theta$ with dimensionless time $\bar{t}$. 


$$
\begin{aligned}
Q(z, t) & =\int_{0}^{t} q(z, t) \mathrm{d} t \\
& =\int_{0}^{t}\left(-\frac{1}{l} \varphi-\frac{2}{l} \varphi \sum_{n=1}^{\infty} \mathrm{e}^{-\frac{n^{2} \pi^{2} a^{2}}{l^{2}} t} \cos \frac{n \pi z}{l}\right) K \mathrm{~d} t \\
& =-\frac{1}{l^{2}} a^{2} \mu_{\mathrm{s}} \varphi l t-\frac{2}{\pi^{2}} \mu_{\mathrm{s}} \varphi l \sum_{n=1}^{\infty} \frac{1}{n^{2}}\left(1-\mathrm{e}^{\frac{n^{2} \pi^{2} a^{2}}{l^{2}}}\right) \cos \frac{n \pi z}{l} .
\end{aligned}
$$

Through non-dimensional transformation, it follows that

$$
\bar{Q}(\bar{z}, \bar{t})=\frac{Q}{\mu_{\mathrm{s}} \varphi l}=-\bar{t}-\frac{2}{\pi^{2}} \sum_{n=1}^{\infty} \frac{1}{n^{2}}\left(1-\mathrm{e}^{-n^{2} \pi^{2} \bar{t}}\right) \cos n \pi \bar{z} .
$$

According to the principle of water balance, the released water in the entire thickness of the aquitard is equal to the cumulative flux per unit horizontal area at location $\bar{z}=1$ minus that at location $\bar{z}=0$ at time $t$. The water balance equation is written as

$$
\int_{0}^{t} q(l, t) \mathrm{d} t-\int_{0}^{t} q(0, t) \mathrm{d} t=F .
$$

On the left-hand side of eq. (18), one has

$$
\begin{aligned}
& \int_{0}^{t}(q(l, t)-q(0, t)) \mathrm{d} t \\
= & \frac{2 \mu_{\mathrm{s}} \varphi l}{\pi^{2}}\left(\sum_{n=1}^{\infty} \frac{1}{n^{2}}\left((-1)^{n}-(-1)^{n} \mathrm{e}^{-\frac{n^{2} \pi^{2} a^{2}}{l^{2}} t}\right)+\sum_{n=1}^{\infty} \frac{1}{n^{2}}\left(1-\mathrm{e}^{-\frac{n^{2} \pi^{2} a^{2}}{l^{2}} t}\right)\right) \\
= & \frac{2 \mu_{\mathrm{s}} \varphi l}{\pi^{2}} \sum_{n=1}^{\infty}\left((-1)^{n}-1\right) \frac{1}{n^{2}} \mathrm{e}^{-\frac{n^{2} \pi^{2} a^{2}}{l^{2}} t}-\frac{2 \mu_{\mathrm{s}} \varphi l}{\pi^{2}} \sum_{n=1}^{\infty}\left((-1)^{n}-1\right) \frac{1}{n^{2}},
\end{aligned}
$$

in which

$$
\sum_{n=1}^{\infty}\left((-1)^{n}-1\right) \frac{1}{n^{2}}=-\frac{\pi^{2}}{4} .
$$

Substituting eq. (20) into eq. (19) yields

$$
\begin{aligned}
& \int_{0}^{t}(q(l, t)-q(0, t)) \mathrm{d} t \\
= & \frac{1}{2} \mu_{\mathrm{s}} \varphi l-\frac{2}{\pi^{2}} \mu_{\mathrm{s}} \varphi l \sum_{n=1}^{\infty} \frac{1}{n^{2}} \mathrm{e}^{-\frac{n^{2} \pi^{2} a^{2}}{l^{2}}}\left(1-(-1)^{n}\right) .
\end{aligned}
$$

Comparison of eq. (21) with eq. (11) confirms the water balance equation (18).

Figure 5 shows the water balance curves as depicted by eq. (18). Curves 1 and 2 represent the cumulative flux at the cross sections of $\bar{z}=0$ and $\bar{z}=1$, respectively. Curve 3 represents the cumulative released water of the aquitard. From the curves in Figure 5, it is seen that there are three different stages. At the initial stage, namely when the dimensionless time is between 0 and 0.1 , the cumulative flux is zero at the cross section $\bar{z}=1$. The cumulative flux increases significantly at the cross section $\bar{z}=0$, resulting

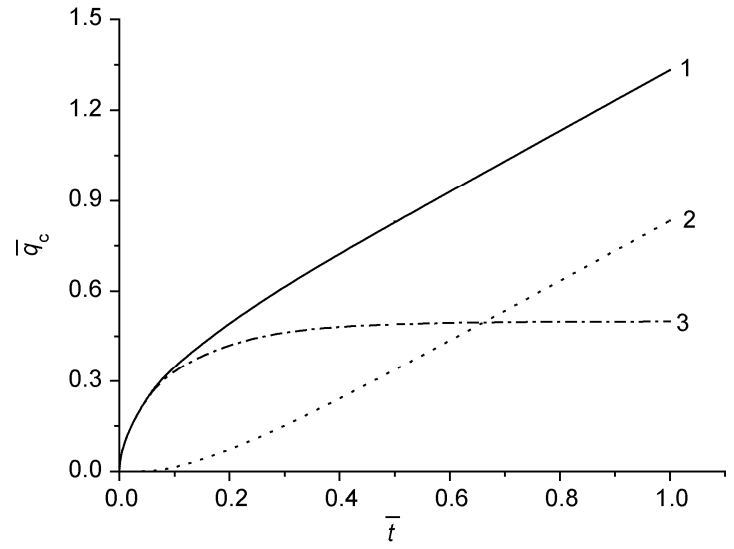

Figure 5 Water balance curves. Curves 1 and 2 represent the cumulative flux at the cross sections $\bar{z}=0$ and $\bar{z}=1$ respectively. Curves 3 represents the cumulative released water of the aquitard.

from the cumulative released water of the aquitard. At the middle stage, when the dimensionless time is between 0.1 and 0.7 , the cumulative flux increases slightly and tends to be uniform at the cross section $\bar{z}=1$. The cumulative released water of the aquitard increases slowly. The cumulative flux increases uniformly at the cross section $\bar{z}=0$, indicating that the underlying aquifer is supplied not only by the released water of the aquitard but also by the leakage recharge of the upper aquifer. At the later stage, when the dimensionless time is greater than 0.7 , the cumulative flux at the cross section $\bar{z}=1$ is larger than the cumulative released water of the aquitard. The main supply source of the cross section $\bar{z}=0$ is the cumulative flux at the cross section $\bar{z}=1$. Curves 1 and 2 are parallel, indicating that the release of water tends to be complete.

When $t=\tau_{0}$ or $t \rightarrow \infty$, it follows from eq. (21) that

$$
\int_{0}^{t}(q(0, t)-q(l, t)) \mathrm{d} t=-\frac{1}{2} \mu_{\mathrm{s}} \varphi l .
$$

Eq. (22) shows that the difference in cumulative flux at the top and bottom is constant. The elastic release of water is complete and there is only leakage recharge. At this time, the inflow and outflow at the top and bottom of the aquitard are equal. The leakage flux is

$$
q_{y}=-K J(l, t)=\frac{\varphi K}{l}+\frac{2}{l} \varphi K \sum_{n=1}^{\infty}(-1)^{n} \mathrm{e}^{-\frac{n^{2} \pi^{2} a^{2}}{l^{2}} t}=\frac{\varphi K}{l} .
$$

According to the principle of water balance, the released water per unit time per unit area of the aquitard should be equal to the difference in the flux at the top and bottom:

$$
\begin{aligned}
q_{z} & =-\mu_{s} \frac{\partial F}{\partial t}=q(0, t)-q(l, t) \\
& =\frac{2}{l} \varphi K \sum_{n=1}^{\infty}\left((-1)^{n}-1\right) \mathrm{e}^{-\frac{n^{2} \pi^{2} a^{2}}{l^{2}} t} .
\end{aligned}
$$

Through non-dimensional transformation, eq. (24) can be 
written as

$$
\overline{q_{z}}(\bar{t})=\frac{l}{\varphi K} q_{z}(t)=2 \sum_{n=1}^{\infty}\left((-1)^{n}-1\right) \mathrm{e}^{-n^{2} \pi^{2} \bar{t}} .
$$

Figure 6 shows the change of the released water per unit time $\bar{q}_{z}$ with dimensionless time $\bar{t}$. It is seen that $\bar{q}_{z}$ decreases with $\bar{t}$.

\section{Theory and method of parameter identifica- tion}

\subsection{Theory of parameter identification}

For the sake of convenience, eq. (15) can be further transformed into dimensionless form:

$$
\bar{q}(\bar{z}, \bar{t})=\frac{l}{\varphi K} q(z, t)=-1-2 \sum_{n=1}^{\infty} \mathrm{e}^{-n^{2} \pi^{2} \bar{t}} \cos n \pi \bar{z}
$$

Letting $\bar{z}=0$ in eq. (26), the variation in flux per unit horizontal area at the bottom of the aquitard (without considering the flux direction and taking a positive value) is obtained. Figure 7 shows how the dimensionless flux $\bar{q}$ changes with dimensionless time $\bar{t}$ at the bottom of the aquitard. It is found that the dimensionless flux $\bar{q}$ reaches its maximum at initial time, and then decreases dramatically with time. When the dimensionless time $\bar{t} \geqslant 1$, that is $t \geqslant \tau_{0}$, the dimensionless flux tends to a constant value $\bar{q}$ $=1$. Similarly, letting $\bar{z}=1$ in eq. (26), the variation in flux per unit horizontal area at the top of the aquitard is obtained.

\subsection{Method of parameter identification}

According to eq. (26), the flux per unit horizontal area at

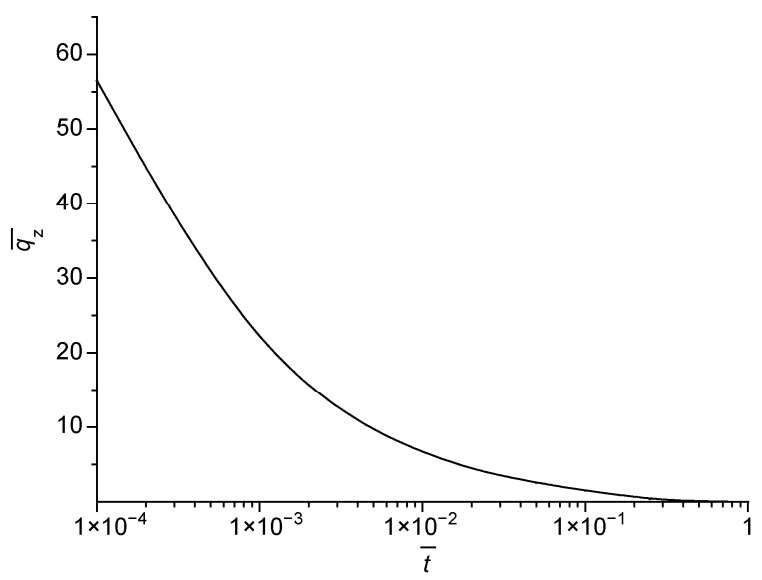

Figure 6 Change of released water per unit time $\bar{q}_{z}$ with dimensionless time $\bar{t}$.

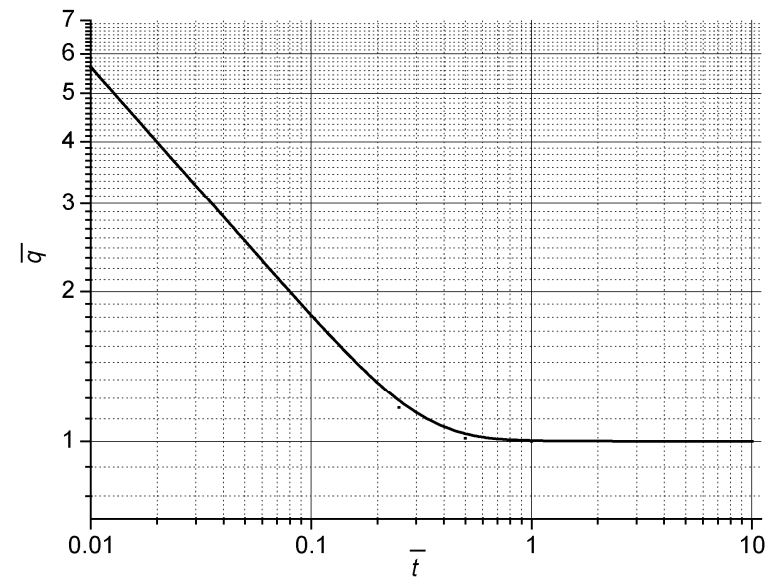

Figure 7 Type curve of dimensionless flux $\bar{q}$ versus dimensionless time $\bar{t}$ at the bottom of the aquitard.

position $\bar{z}=0$ and time $\bar{t}$ can be written as

$$
\bar{q}(0, \bar{t})=\frac{l}{\varphi K} q(0, t) .
$$

In addition, one has

$$
\bar{t}=\frac{a^{2}}{l^{2}} t
$$

The logarithmic forms of eqs. (27) and (28) are

$$
\begin{aligned}
\lg \bar{q}(0, \bar{t}) & =\lg q(0, t)+\lg \frac{l}{\varphi K}, \\
\lg \bar{t} & =\lg t+\lg \frac{a^{2}}{l^{2}} .
\end{aligned}
$$

The second terms in both eq. (29) and eq. (30) are constant. Therefore, on the logarithmic graph, the experimental curve of the flux $q(0, t)$ versus time $t$ is analogous to the type curve of the dimensionless flux $\bar{q}$ versus dimensionless time $\bar{t}$ at $\bar{z}=0$ as shown in Figure 7 . There is a difference of $a^{2} / l^{2}$ along the horizontal axis and $l / \varphi K$ along the vertical axis between the two curves. Here the type-curvefitting method is used. The curve of $q(0, t)$ versus $t$ is superposed on the type curve of $\bar{q}$ versus $\bar{t}$ keeping the axes of the two graphs parallel. In the matched position, a point at the intersection of the major axes of the type curve is selected and marked on the curve of $q(0, t)$ with respect to $t$. Match-point coordinates $[\bar{q}],[q],[\bar{t}]$ and $[t]$ are substituted into eqs. (27) and (28) to determine the parameters, namely the hydraulic conductivity, hydraulic diffusivity and specific storativity:

$$
\begin{aligned}
K & =\frac{[q] l}{[\bar{q}] \varphi}, \\
a^{2} & =\frac{[\bar{t}]}{[t]} l^{2},
\end{aligned}
$$




$$
\mu_{\mathrm{s}}=\frac{K}{a^{2}} .
$$

When $t=\tau_{0}$ or $t \rightarrow \infty$, the elastic yield of the aquitard vanishes entirely and there is only leakage recharge in the aquifer. The fluxes at the top and bottom of the aquitard in unit time are equal, and therefore denoted as $q_{y}$. The hydraulic conductivity can also be obtained using eq. (23):

$$
K=\frac{l}{\varphi} q_{y} .
$$

In addition, according to eq. (26), the dimensionless flux at position $\bar{z}=1$ and time $\bar{t}$ is given by

$$
\bar{q}(l, \bar{t})=\frac{l}{\varphi K} q(l, t) .
$$

The logarithmic form of eq. (35) is

$$
\lg \bar{q}(l, \bar{t})=\lg q(l, t)+\lg \frac{l}{\varphi K} .
$$

From eqs. (36) and (30), the hydrogeological parameters can be estimated using the type curve method.

\section{Experimental verification}

\subsection{Laboratory apparatus and procedures}

To test the groundwater dynamics and water balance characteristics of the aquitard under the condition of the water level in the aquifer declining significantly, a physical model experiment was carried out. The prototype of the test device is shown in Figure 8. The test device consists of a consolidation container, base, flanges, piezometric tube, permeable filter paper, overflow tank, water tank, stand, dial indicator and retractable hard plastic rod. It can provide the supply and drainage of water, and measure the pore pressure, subsidence and flux during the test. The apparatus for the test is an organic glass cylinder with height of $205 \mathrm{~cm}$, outside diameter of $40 \mathrm{~cm}$ and inside diameter of $38 \mathrm{~cm}$. The organic glass cylinder consists of three parts from top to bottom: a lower filter layer, middle layer filled with soil for testing, and upper layer through which water flows. The soil samples used in the experiment were medium sand (50\% of particles being larger than 0.25$)$, fine sand ( $85 \%$ of particles being larger than 0.075) and silty clay. According to the Standard for soil test method (GB/T50123-1999), Specifica- tion of Soil Test (SL237-1999) and Code for investigation of geotechnical engineering (GB50021-2001), the basic physical parameters of the soil were tested, as listed in Table 1. The conventional consolidation test was conducted five times for the soil sample in the silty clay before the experiment. The void ratio of the soil was 1.28 before the consolidation test. The pressure on the soil was 50, 100, 200, 400 and $800 \mathrm{kPa}$, respectively. A void ratio-pressure plot (e-p curve) was derived. The average void ratio was determined to be 0.86 from the curve.

The aquifer system consists of an upper sand layer, middle silty clay layer and lower sand layer. The lateral boundary of the aquifer system is impermeable. The hydraulic head at the top of the upper sand layer and that at the bottom of the lower sand layer are fixed. The hydraulic head in each layer was initially constant. The hydraulic head in the lower sand layer declined dramatically by $\varphi$ initially, and then remained during the experiment. We measured the drainage flux at the bottom of the aquifer, the head in the pressure tube and subsidence variation in each layer. The specific steps were as follows:

(1) Check the test device: Ensure that the piezometric tube is unblocked, the end of the tube wrapping the sand is undamaged, and the test instrument is operating normally.

(2) Fill apparatus with the sample: Use a clean rag to wipe the inner wall of the consolidation container, and then spread a layer of grease or Vaseline on the inner wall. Inject hot water into the consolidation container through the overflow tank, and raise the water surface slowly. During water injection, pay attention to whether there is a bubble stranded in the filter layer, and if so, try to discharge it. Close valve $V_{2}$ to stop water injection when the water surface reaches the position of the first piezometric tube. Remove the sand sample that was wetted previously, and fill the consolidation container with sand and clay. Note that the piezometric tube needs to be buried when filling the piezometric tube to the designed level. After the lower sand layer and middle silty clay layer are poured, place the device for measuring the subsidence in each layer. Stand for about 24 hours in each layer, and then fill the next layer.

(3) Saturate the sample: Connect the sealed lid and consolidation container with the flange, and ensure that the consolidation container does not leak air. Turn off all valves except the exhaust valve, and pump out the air in the container with a vacuum pump. Increase the negative pressure within the consolidation container gradually, such as in the sequence $-0.02,-0.04,-0.06,-0.08$ and $-0.1 \mathrm{MPa}$. The

Table 1 Physical and mechanical properties of the sample

\begin{tabular}{lcccc}
\hline Soil sample & Dry density $\left(\mathrm{g} / \mathrm{cm}^{3}\right)$ & Saturated density $\left(\mathrm{g} / \mathrm{cm}^{3}\right)$ & Void ratio & Compression index \\
\hline Medium sand & 1.60 & 2.00 & 0.66 & - \\
Fine sand & 1.51 & 1.93 & 0.73 & - \\
Silty clay & 0.883 & 1.88 & 0.86 & 0.36 \\
\hline
\end{tabular}




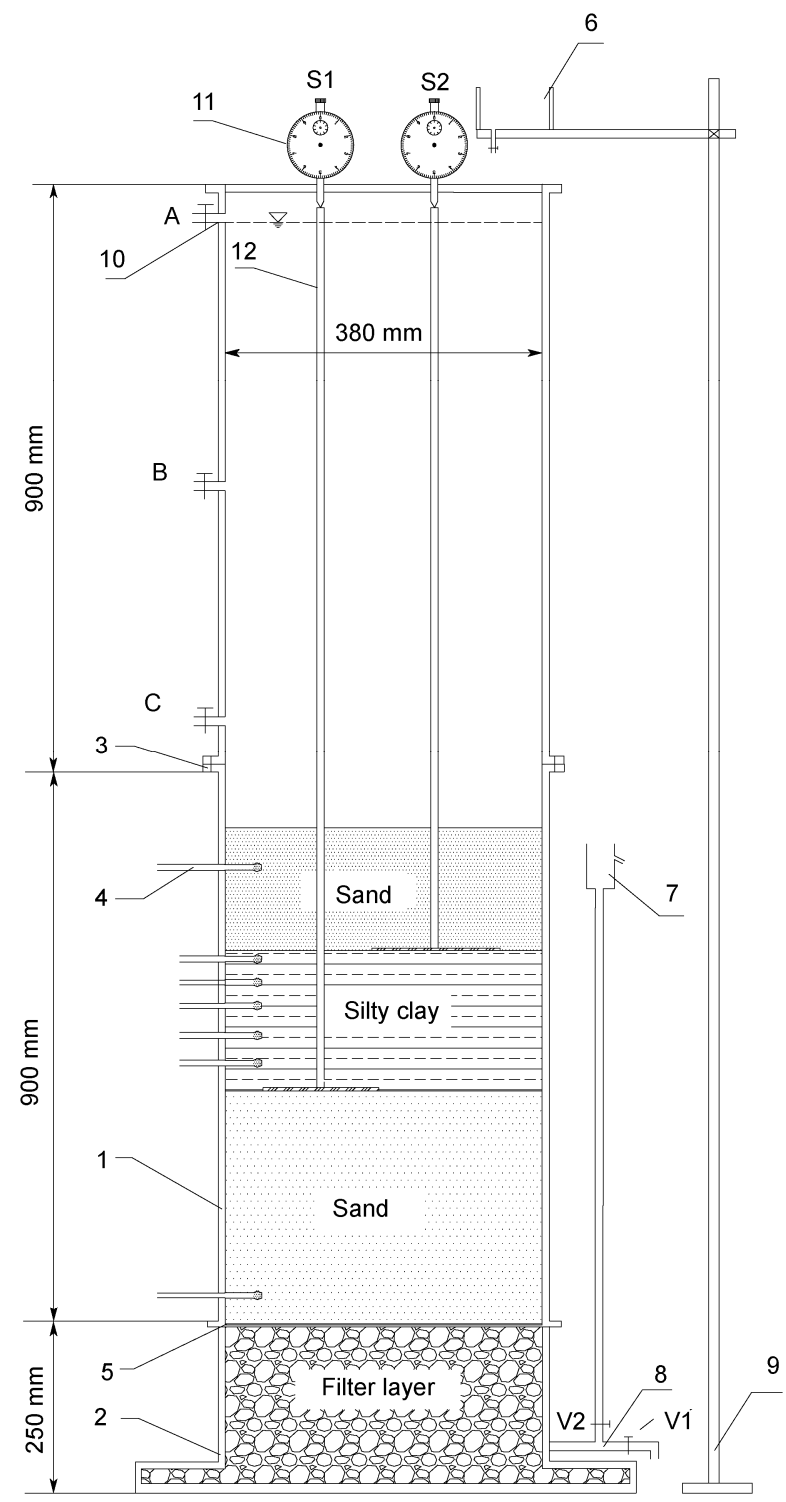

Figure 8 Prototype of the test device. 1, Consolidation container; 2, base; 3 , flanges; 4 , piezometric tube; 5 , permeable filter paper; 6 , water tank; 7 , overflow tank; 8 , three-way valve; 9 , stand; 10 , overflow pipe; 11 , dial indicator; 12 , rigid rod.

interval time for each level of negative pressure is 12 hours.

(4) After the soil layer is poured, add water to elevation A (or B and C) slowly. Open the valve of the sink, and provide water to the device. To allow excess water to overflow, open valve A. Then adjust the dial indicator appropriately and fix it, and record the initial reading. Observe the dial indicator once for several minutes, until the readings on the dial indicator remain unchanged. At this time, the hydraulic head in the piezometric tube should be basically consistent. The process generally takes a few days.

(5) Record the initial head in the piezometric tube and the readings on the dial indicator of S1 and S2. Adjust the overflow tank to the designed height, and fill it with water. After everything is ready, open the valve V2. The confined hydraulic head in the aquifer decreases by $\varphi$ and then re- mains constant. At the same time, record the readings in each piezometric tube at $5 \mathrm{~s}, 10 \mathrm{~s}, 30 \mathrm{~s}, 1 \mathrm{~min}, 2 \mathrm{~min}, 4 \mathrm{~min}$, $8 \mathrm{~min}$ and $12 \mathrm{~min}$. We should also record the readings on the dial indicator of S1 and S2, and measure the flux at the outlet of the overflow tank using a graduated cylinder. Water is stored in the graduated cylinder for $60 \mathrm{~s}$ at each measurement, as controlled by a stopwatch. Flux is recorded when water is initially stored in the graduated cylinder.

(6) Observe continuously until the readings on the dial indicator and piezometric tube do not change, and then terminate the test.

\subsection{Experiment and parameter estimation}

A middle silty clay layer with thickness of $20 \mathrm{~cm}$ represented the aquitard. The thicknesses of the upper and lower sand aquifers were 20 and $30 \mathrm{~cm}$, respectively. The hydraulic heads in the aquitard and those in the upper and lower aquifers were equal before the experiment. When the pore water pressure reached the hydrostatic pressure in the aquitard, the valve $V_{2}$ was opened. The hydraulic head in the lower confined aquifer declined dramatically (by $\varphi=1.2 \mathrm{~m}$ ) at the beginning of the experiment, and then remained constant during the remainder of the experiment. The flux variation with time at the lower overflow tank outlet was observed and recorded, as reported in detail in Table 2. The observation time of the experiment was 1760 minutes. At the end of the observation, the flux tended to be steady.

The value of the flux per unit area $(q)$ can be calculated by dividing the flux $(Q)$ as listed in Table 2 by the horizontal area of the cylinder $(S)$, where $S$ is $1134.11 \mathrm{~cm}^{2}$. The measured value of $q(0, t)$ versus $t$ is plotted with double logarithmic axes as shown in Figure 9. The type curve of $\bar{q}$ versus $\bar{t}$ is then superposed on the measured values, keeping the axes of the two graphs parallel (Figure 9). The initial five observation points for flux deviate from the type curve. The reason is that the flux decreased dramatically at the initial stage, and flux is recorded for the initial time that water is stored in the graduated cylinder. Therefore, the calculated test flux is lower. The error is greater when the observation point is closer to the beginning stage.

Table 2 Results of the flux data with time

\begin{tabular}{cccccccc}
\hline$t(\mathrm{~min})$ & $Q(\mathrm{~mL} / \mathrm{s})$ & $t(\mathrm{~min})$ & $Q(\mathrm{~mL} / \mathrm{s})$ & $t(\mathrm{~min})$ & $Q(\mathrm{~mL} / \mathrm{s})$ & $t(\mathrm{~min})$ & $Q(\mathrm{~mL} / \mathrm{s})$ \\
\hline 3 & 0.4717 & 56 & 0.1650 & 154 & 0.1283 & 420 & 0.1117 \\
7 & 0.3717 & 65 & 0.1567 & 165 & 0.1200 & 480 & 0.1133 \\
9 & 0.3283 & 75 & 0.1517 & 181 & 0.1217 & 600 & 0.1150 \\
13 & 0.2917 & 85 & 0.1433 & 210 & 0.1233 & 720 & 0.1133 \\
17 & 0.2500 & 96 & 0.1483 & 225 & 0.1183 & 820 & 0.1150 \\
22 & 0.2350 & 105 & 0.1367 & 240 & 0.1183 & 1415 & 0.1083 \\
27 & 0.2150 & 115 & 0.1333 & 270 & 0.1183 & 1440 & 0.1100 \\
35 & 0.1983 & 125 & 0.1317 & 300 & 0.1150 & 1560 & 0.1100 \\
45 & 0.1783 & 135 & 0.1300 & 361 & 0.1133 & 1760 & 0.1083 \\
\hline
\end{tabular}




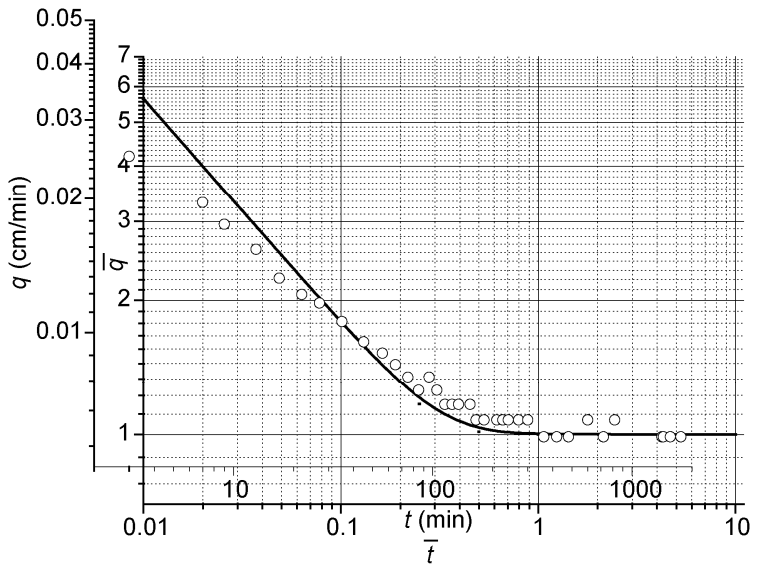

Figure 9 Experimental data matched with the type curve. The soild line is the type curve, and the symbols represent the observation data.

A matched position at the major axes of the type curve is selected and marked on the curve of $q(0, t)$ versus $t$, such as $[\bar{q}]=2,[q]=0.0115,[\bar{t}]=0.1$ and $[t]=32$. The parameters can be obtained by substituting these values into eqs. (31)-(33):

$$
\begin{gathered}
K=\frac{[q] l}{[\bar{q}] \varphi}=\frac{0.0115 \times 20}{2 \times 120}=9.583 \times 10^{-4}(\mathrm{~cm} / \mathrm{min}), \\
a^{2}=\frac{[\bar{t}]}{[t]} l^{2}=\frac{0.1}{32} \times 20^{2}=1.25\left(\mathrm{~cm}^{2} / \mathrm{min}\right) \\
\mu_{\mathrm{s}}=\frac{K}{a^{2}}=\frac{0.01378}{0.18}=7.65 \times 10^{-2}(1 / \mathrm{m}) .
\end{gathered}
$$

Using eq. (10), the delay index is obtained as

$$
\tau_{0}=\frac{l^{2}}{a^{2}}=\frac{20^{2}}{1.25}=320.0(\mathrm{~min}) .
$$

To verify the estimated parameter, eq. (34) can also be used to derive the hydraulic conductivity. Taking the flux $(Q=0.115 \mathrm{~mL} / \mathrm{s})$ at around time $t=\tau_{0}$, namely $t=300 \mathrm{~min}$, as shown in Table 2, one has

$$
K=\frac{l}{\varphi} q_{y}=\frac{l Q}{\varphi S}=\frac{20 \times 0.115 \times 60}{120 \times 1134.11}=1.014 \times 10^{-3}(\mathrm{~cm} / \mathrm{min}) .
$$

The relative error between eq. (41) and eq. (37) for the hydraulic conductivity is only $5.5 \%$.

\subsection{Parameter validation}

Substituting the hydrogeological parameters estimated using the type curve method into eq. (15), the calculated flux $(Q(t)=q(0, t) S)$ corresponding to the observation time at the bottom of aquitard is obtained. Figure 10 compares the estimated and measured fluxes. The coefficient of correlation between them is 0.976 , indicating that the estimated fluxes

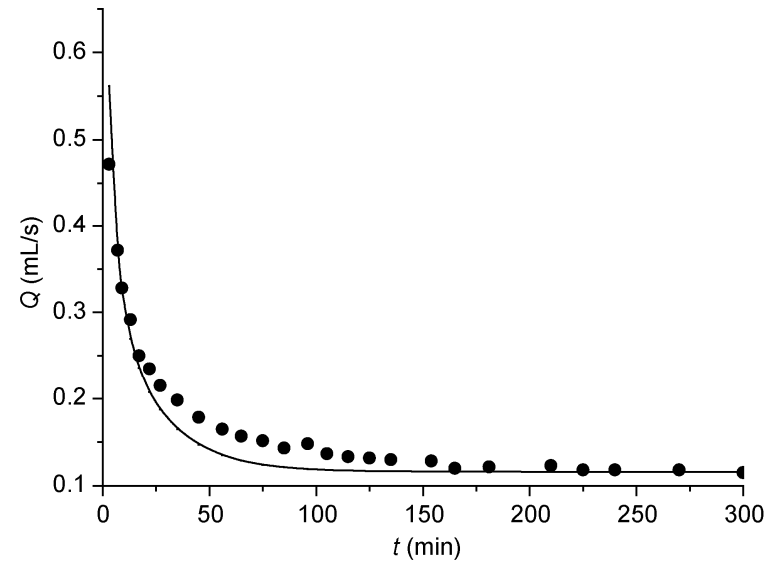

Figure 10 Comparison of estimated fluxes and measured values. Dots represent the observed data, and the curve represents the computed data.

are consistent with measured values.

\section{Conclusions}

An analytical solution for the drawdown variation in an aquitard was derived, under the condition that the head in the adjacent confined aquifer declines by a constant value. The characteristics of groundwater dynamics and water balance of the aquitard were analyzed according to the dimensionless analytical solution. A new method for determining hydrogeological parameters is presented. The main conclusions are as follows:

(1) When the hydraulic head of the confined aquifer declines by $\varphi$, the response of groundwater dynamics in the aquitard is obviously delayed. The delay index $\tau_{0}$ represents the time of the delayed response of the drawdown in the aquitard relative to drawdown variation in the aquifer. The delay index $\tau_{0}$ is only dependent on the properties and thickness of the aquitard, and the properties of the confined aquifer have no effect.

(2) A formula for computing the delayed release of water in the aquitard was derived. The law for the delayed release of water is described in terms of the ratio of delayed release of water. Within an initial time of $\tau_{0} / 5,85 \%$ of the amount of delayed-release water releases in the aquitard. When time $t$ equals $\tau_{0}$, all delayed-release water in the aquitard has released.

(3) The analytical solution for cumulative flux per unit horizontal area of the aquitard was derived. A water balance equation was established to describe the relation among the recharge, discharge and released water of the aquitard. Combining with the water balance curves, the three stages of the water balance and the corresponding characteristics were obtained.

(4) An analytical solution was given to analyze the flux per unit horizontal area of the aquitard. Hydrogeological parameters of the aquitard, namely the hydraulic conductiv- 
ity, specific storativity and hydraulic diffusivity, were estimated from type-curve fitting between the analytical solution and observed flux. The calculated flux predicted by the analytical solution is in good agreement with the observation data, indicating that the estimated parameters can characterize the groundwater flow in the aquitard. The method has many advantages. The apparatus and experimental process are simple and convenient. The apparatus can also be used to measure in-situ hydrogeological parameters. The type-curve-fitting method used to determine the parameters is simple and easy. One experiment can obtain many parameters, such as the hydraulic conductivity, hydraulic diffusivity and specific storativity. The precision of the estimated parameters is high, because the flux measurement is easy to implement and the error is relatively small. Therefore, the method for estimating the hydrogeological parameters of the aquitard has good application value.

This work was supported by the National Natural Science Foundation of China (41172204).

1 Konikow L F, Neuzil C E. A method to estimate groundwater depletion from confining layers. Water Resour Res, 2007, 43: W07417

2 Neuzil C E. Groundwater flow in low-permeability environments. Water Resour Res, 1986, 22: 1163-1195
3 Yang Y L, Aplin A C. Permeability and petrophysical properties of 30 natural mudstones. J Geophys Res-Sol Ea, 2007, 112: B03206

4 Yang Y L, Aplin A C. A permeability-porosity relationship for mudstones. Mar Petrol Geol, 2010, 27: 1692-1697

5 Hart D J, Bradbury K R, Feinstein D T. The vertical hydraulic conductivity of an aquitard at two spatial scales. Ground Water, 2006, 44: 201-211

6 Neuzil C E. How permeable are clays and shales? Water Resour Res, 1994, 30: $145-150$

7 Sun D M, Zhan H B. Flow to a horizontal well in an aquitard-aquifer system. J Hydrol, 2006, 321: 364-376

8 Malama B, Kuhlman K L, Barrash W. Semi-analytical solution for flow in leaky unconfined aquifer-aquitard systems. J Hydrol, 2007, 346: 59-68

9 Malama B, Kuhlman K L, Barrash W. Semi-analytical solution for flow in a leaky unconfined aquifer toward a partially penetrating pumping well. J Hydrol, 2008, 356: 234-244

10 Berg S J, Hsieh P A, Illman W A. Estimating hydraulic parameters when poroelastic effects are significant. Ground Water, 2011, 49: 815-829

11 Yeh H D, Chang Y C. Recent advances in modeling of well hydraulics. Adv Water Resour, available online 14 March 2012, in press

12 Zhou Z F, Guo G X, Wang B H, et al. Double-layer structure model and FEM calculation of dewatering of deep foundation pits (in Chinese). J Hohai Univ (Nat Sci), 2004, 32: 179-183

13 Zhou Z F, Zhu H G, Chen J, et al. Nonlinear coupling calculation between dewatering and settlement of deep foundation pit (in Chinese). Rock Soil Mech, 2004, 25: 1984-1988

14 Hantush M S. Modification of the theory of leaky aquifers. J Geophys Res, 1960, 65: 3713-3716

15 Neuman S P, Witherspoon P A. Theory of flow in a confined two aquifer system. Water Resour Res, 1969, 5: 803-816

Open Access This article is distributed under the terms of the Creative Commons Attribution License which permits any use, distribution, and reproduction in any medium, provided the original author(s) and source are credited. 